\title{
Modeling and Simulation Using Circular Spiral Antenna Array for RF Harvesting
}

\author{
Kang Chia Chao ${ }^{1}$, Mohd F.Ain ${ }^{1}$, Ihsan A. Zubir ${ }^{1}$ \\ ${ }^{1}$ School Of Electrical And Electronic Engineering, Engineering Campus, Universiti Sains Malaysia \\ 14300 Nibong Tebal, Penang Malaysia
}

\begin{abstract}
The design of radio frequency $(R F)$ energy harvesting by using circular planar spiral inductor antenna arrays is proposed. The proposed antenna is a $2 x 1$ circular spiral inductor. The size, return loss and radiation patterns were studied. It is expected that the proposed method is capable of harvesting RF electromagnetic energy more efficiently compared to when using single element spiral antenna. Both circular spiral inductors are fabricated on Roger 4003 substrates. Simulation results show that 5.14dBi gain for antenna array and 3.22dBi gain for single antenna can be achieved at frequency $527 \mathrm{MHz}$. The gain has increased about $37.3 \%$ on the antenna array. Besides, practical results show that circular spiral inductor antenna array harvested more energy than a single element antenna. Therefore, the results obtained are a very attractive alternative design solution for energy harvesting system in the future. The array method of the circular spiral inductor antenna is successfully confirmed.
\end{abstract}

Keywords: Antenna array, Energy harvesting, Planar spiral inductor

\section{INTRODUCTION}

In recent years, energy harvesting has been the focus of many research and development. For example, different types of source like piezoelectric, RF source or solar energy can be harvested and convert into useful DC power [1]. As the RF energy is available everywhere and anytime, this is the very reason why RF source has been very attractive. Therefore, it can either reduce or eliminate the low power integrated circuits that have wired power sources [2]. In this paper, a novel antenna array is proposed. The antenna will detect the radio frequency and will convert the electromagnetic wave into voltage response. Due to the amount of RF ambient sources been captured is extremely low, the output of the single patch antenna does not provide sufficient energy [3] to use in any application. Hence, these works were focused on design, simulate and measured of antenna array to capture electromagnetic energy from RF sources that have been radiated by the communication system in the range of $500 \mathrm{MHz}$ and $10 \mathrm{GHz}$ [4]. The momentum simulation method in ADS2008 was used to simulate and design for single element and antenna array [5].

\section{Material AND Method Of Design}

This section presents the material and design method of using $2 \mathrm{x} 1$ array circular planar spiral inductor that will use to harvest RF power. The PCB board used in this design is Duroid 4003 from Roger corps with the dielectric constant $\varepsilon_{\mathrm{r}}=3.38$, loss tangent of 0.0027 , thickness of the ground layer is $0.035 \mathrm{~mm}$ and the parameter of the circular spiral inductor is given in Table 1 . The proposed antenna array was excited by $50 \mathrm{ohm}$ microstrip feeder.

Table 1: Parameter of Spiral Inductor

\begin{tabular}{c|c}
\hline \hline Parameter & Value \\
\hline \hline No. of Turn, N & 10.5 \\
Width, W & $2 \mathrm{~mm}$ \\
Spacing, S & $0.5 \mathrm{~mm}$ \\
Inner Diameter, Din & $2.4 \mathrm{~mm}$ \\
\hline \hline
\end{tabular}






Fig. 1: Single Antenna [6]

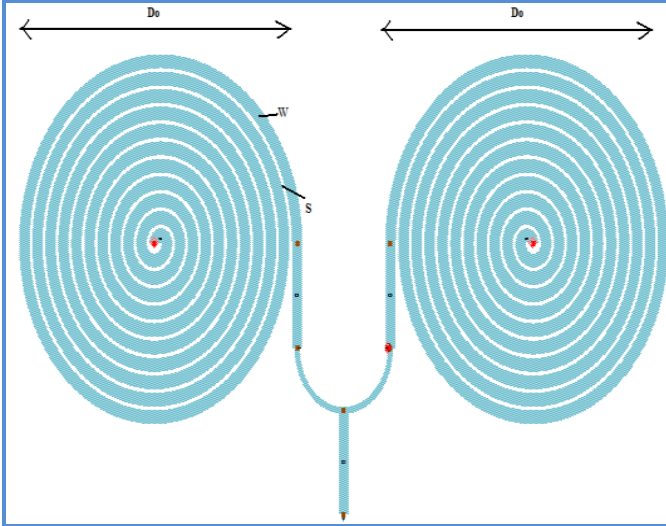

Fig. 2: 2x1 Antenna Array

III. MODELING AND EQUATIONS

Lumped element inductors such as spiral inductor are key techniques for reducing monolithic microwave integrated circuit (MMIC) chip area. Inductors used as such circuit components, play a significant role in the realization of compact integrated chips, resulting in more chips per wafer and thus, lower cost. The model aims to design the value of RLC lumped elements as described in Fig. 3 below.

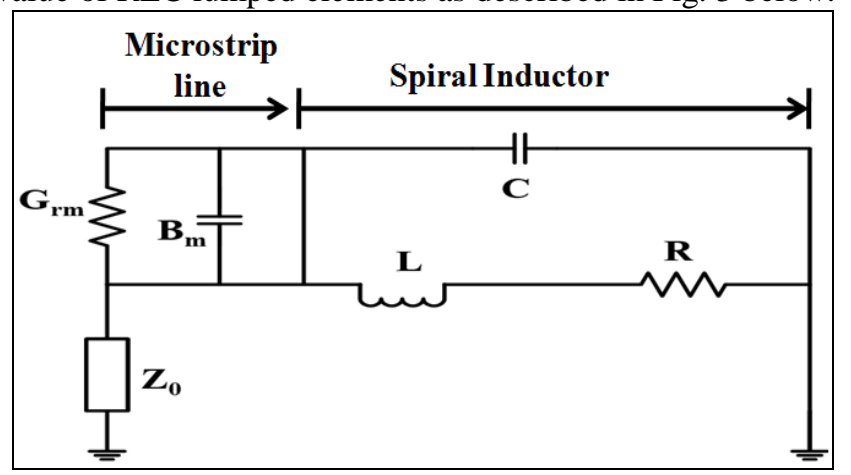

Fig. 3: ADS modeling of a microstrip line feed single spiral inductor

The input feed represent the microstrip line of Grm [7] where $\mathrm{h}$ is substrate height, $\varepsilon_{\text {eff }}=$ effective dielectric constant, $\mathrm{Z}_{\mathrm{cm}}$ is the impedance of microstrip line, $c$ is the velocity of light and $l_{e q}$ corresponds to the inductance of width $W_{s}$ of the microstrip line [8] and lastly $B_{m}=\omega C_{l}$.

$$
\begin{gathered}
G_{r m}=\frac{160 \pi^{2} h^{2}}{Z_{c m}{ }^{2} \lambda_{0}{ }^{2} \varepsilon_{e f f}} \\
C_{l}=\frac{l_{e q} c \sqrt{\varepsilon_{e f f}}}{Z_{c m}}, \text { where } l_{e q}=\left[Z_{c m} \sqrt{\varepsilon_{e f} f}\right] W_{s} / c
\end{gathered}
$$

\subsection{Inductance, $\mathrm{L}$}

The circular spiral inductor represents the lumped element of the RLC. The amount of magnetic energy storage is represented by an inductor L [9] given in (3) as

$$
L=\left[\frac{\mu \cdot N^{2} \cdot d_{\text {avg }}}{2}\right] \cdot\left[\ln \left(\frac{2.46}{\rho}\right)+0.2\left(\rho^{2}\right)\right]
$$

where $\mu$ is the magnetic permeability of the copper traces, $\mathrm{N}$ is the total of turns, $\mathrm{d}_{\text {avg }}$ is given in (4) as

$$
\left.d_{\text {avg }}=\frac{\left(d_{o}+d_{i}\right)}{2}, \text { where } d_{o}=d_{i}+2 N w+2(N-1) s\right)
$$


The parameter $\rho$ is the fill ratio as given in (5) will tend to became one if the turns fill all the areas of the inductor but will tend to zero if the turns are concentrated close to the external perimeter.

$$
\rho=\left(\frac{\left(d_{o}-d_{i}\right)}{\left(d_{o}+d_{i}\right)}\right)
$$

\subsection{Resistance, $\mathbf{R}$}

The series resistance of the model is independent of the frequency and is described by the Ohm's Law. The expression of the series resistance is given in (6)

$$
R_{s}=\rho l\left(\frac{1}{w t}+\frac{1}{2 \delta(t+w)}\right), \text { where } \delta=\sqrt{\frac{2 \rho}{w \mu}}
$$

\subsection{Capacitance, $\mathrm{C}$}

Parallel capacitor is very important in the RLC lumped element. This component will determine the self-resonance frequency of the inductor. In order to obtain the $\mathrm{C}_{\mathrm{T}}=\mathrm{C}_{\mathrm{sub}}+\mathrm{C}_{\text {air }}$, the capacitance between adjacent tracks and the substrate, the air can be express as [10]

$$
\begin{aligned}
& C_{\text {sub }}=\varepsilon_{0} \varepsilon_{r} \frac{K\left(k^{\prime}\right)}{2 K(k)}, \text { where } k=\frac{\tanh \left(\frac{\pi a}{4 h}\right)}{\tanh \left(\frac{\pi s}{4 h}+\frac{\pi w}{2 h}\right)} \& k^{\prime}=\sqrt{1-k^{2}} \\
& C_{\text {air }}=\varepsilon_{0}\left(\frac{K\left(k_{0}^{\prime}\right)}{2 K\left(k_{0}\right)}\right), \text { where } k_{0}=\frac{s}{2 w+s} \& k_{0}^{\prime}=\sqrt{1-k_{0}^{2}}
\end{aligned}
$$

\section{IV.}

\section{RESULTS}

The simulation and experiment outcome is described in this section. The return loss of the single element and $2 \times 1$ antenna array is $-9.42 \mathrm{~dB}$ and $-31.372 \mathrm{~dB}$ respectively when the resonance frequency is at $527 \mathrm{MHz}$. The resonance frequency can be determined using the formula as stated in Equation 9.

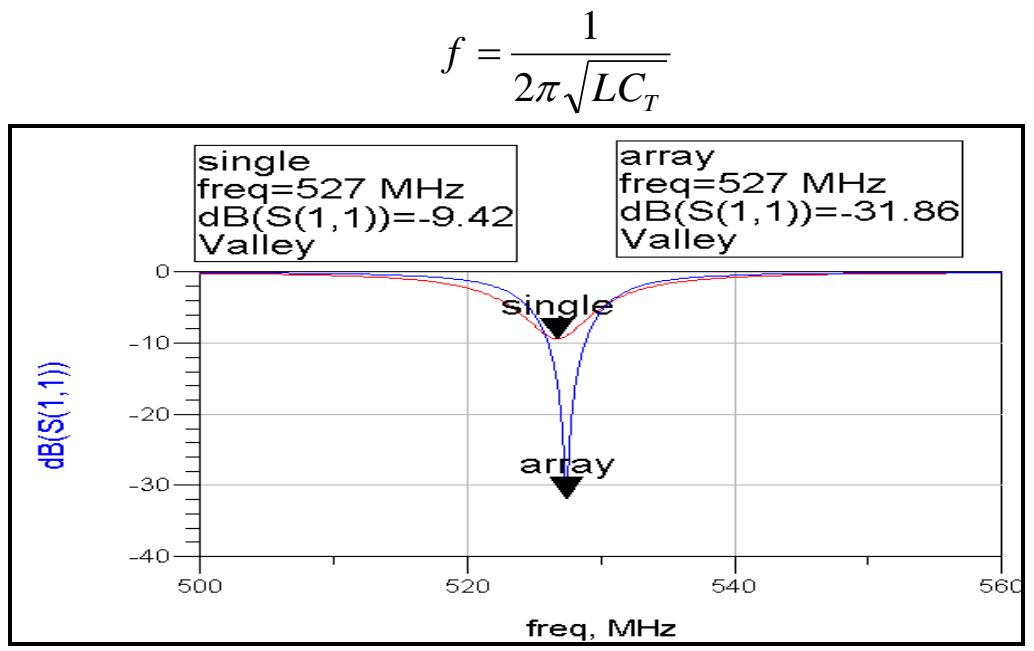

Fig. 4: S11 return loss

The antenna array is designed to increase the gain of the single planar spiral antenna. Figure $5 \& 6$ represent the modeled gain of single element and $2 \times 1$ element array. The gain of the $2 \times 1$ antenna array is $5.14 \mathrm{dBi}$ compare to the single planar spiral antenna which is only $3.22 \mathrm{dBi}$ respectively at resonant frequency of $527 \mathrm{MHz}$. The $2 \mathrm{D}$ gain plot pattern between the two antennas is shown as below. 


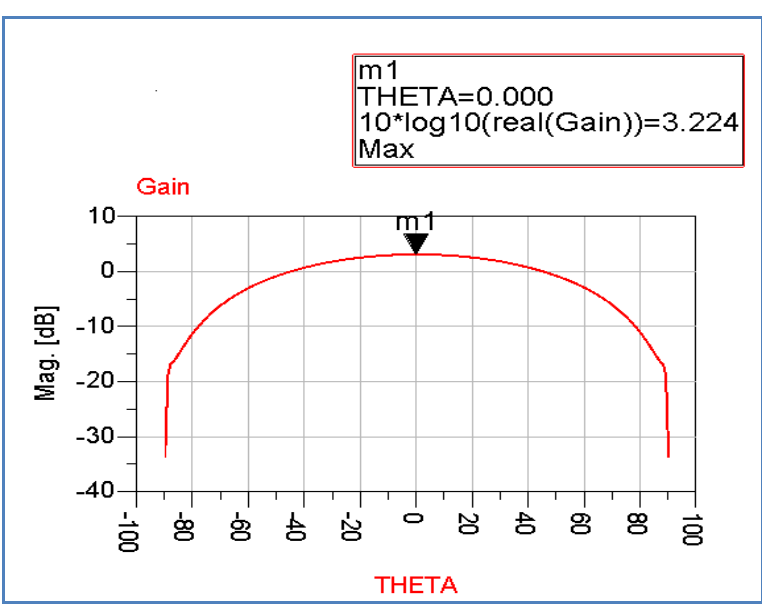

Fig. 5: 2D gain plot of single antenna

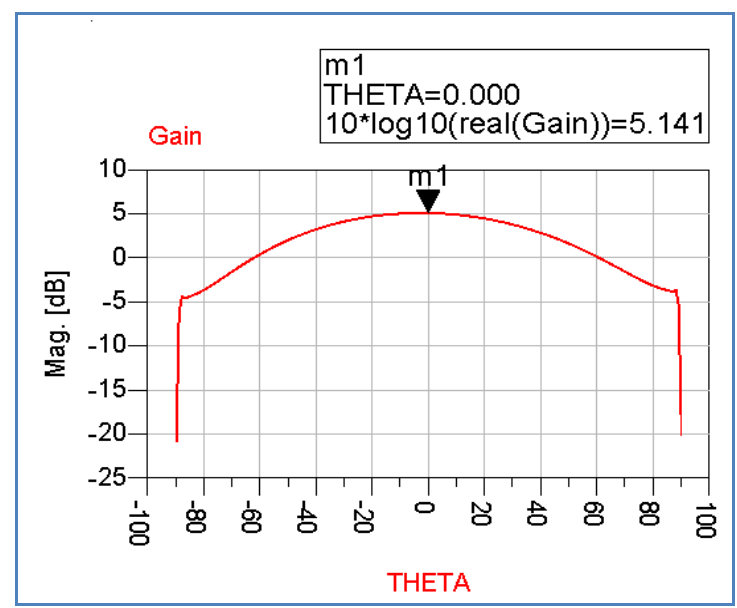

Fig. 6: 2D gain plot of antenna array

Once the gain of the antenna is increased, the energy that collected in terms of voltage response will be enhanced. The Figure 7 shows the comparison measurement results between the two antennas.

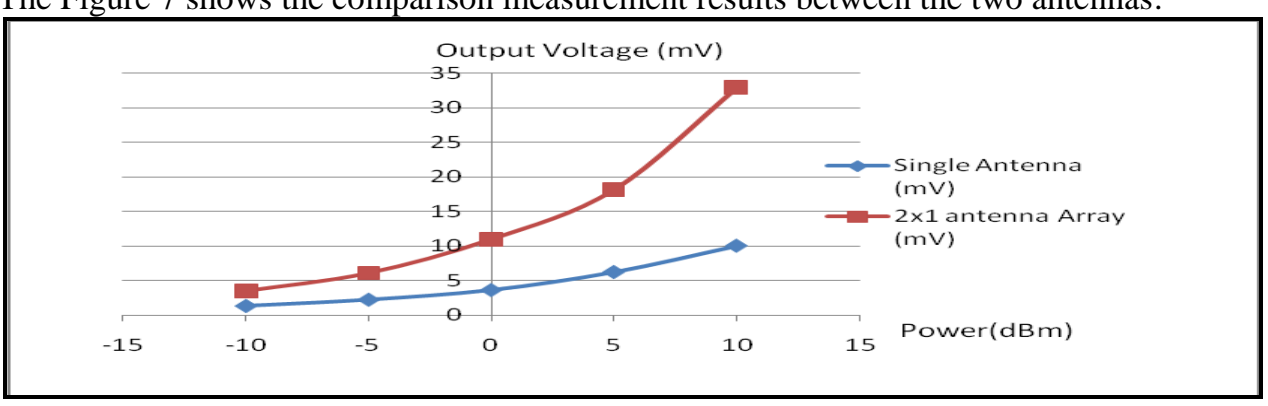

Figure 7: Harvester's voltage response to different input power

From the graph above, it can show that if the spiral inductor is designed in a large scale array, for example, $2 \times 1$ array or $4 \times 1$ array, the energy that the captured by the spiral inductor will be increase and can be used to store in rechargeable battery.

\section{CONCLUSION}

In this paper, study of antenna array for RF energy harvesting has been made and good high gain performance was obtained compared to the single element antenna. It is confirmed that with more antenna array [11], the gain will be increasing and subsequently increase in voltage response. In all, there is a good agreement between the simulated, modelled and measured results.

\section{Acknowledgements}

The authors gratefully acknowledge that this work was financially supported by the USM Research University (RU) -PRGS 1001/PELECT/8046016

[1] TARIS, T., VIGNERAS, V. \& FADEL, L. Year. A 900MHz RF energy harvesting module: New Circuits and Systems Conference (NEWCAS), 2012 IEEE 10th International, 2012. IEEE, 445-448.

[2] BARCAK, J. M. \& PARTAL, H. P. Year. Efficient RF energy harvesting by using multiband microstrip antenna arrays with multistage rectifiers: Subthreshold Microelectronics Conference (SubVT), 2012 IEEE, 9-10 Oct. 2012 2012. 1-3.

[3] MARSHALL, B. R. \& DURGIN, G. D. 2013. Staggered Pattern Charge Collection: Antenna Technique to Improve RF Energy Harvesting. IEEE RFID 2013.

[4] JABBAR, H., SONG, Y. S. \& JEONG, T. T. 2010. RF energy harvesting system and circuits for charging of mobile devices. Consumer Electronics, IEEE Transactions on, 56, 247-253.

[5] NATH, S. \& RANA, S. The Design and Development of Microstrip Patch Antenna using simulation studies by ADS. IJESS.

[6] BAHL, I. J. 2003. Lumped elements for RF and microwave circuits (Artech house)

[7] N. Hasan, S. K. Giri, "Design of low power RF to DC generator for energy harvesting applications," Internationa Journal of Applied Sc. \& Engg., Vol. 1, Iss. 4, pp. 562-568, 2012

[8] I. J. Bahl, \& P. Bhartia, Microstrip Antennas (Artech House, 1980)

[9] Olivo, J., S. Carrara, and G. De Micheli. Modeling of printed spiral inductors for remote powering of implantable biosensors in Medical Information \& Communication Technology (ISMICT), 2011 5th International Symposium on. 2011.

[10] Brian C.Wadell, Transmission Line Design Handbook (Artech House, 1991)

[11] USHIJIMA, Y., SAKAMOTO, T., NISHIYAMA, E. \& AIKAWA, M. Year. $\quad$ Extensible $\quad$ rectifying antenna for large scaleintegration: Microwave Conference Proceedings (APMC), 2011 Asia-Pacific, 2011. IEEE, 1198-1201. 